\title{
Electroactive Surfaces Based on Conducting Polymers for Controlling Cell Adhesion, Signaling, and Proliferation
}

\author{
Edwin Jager, Maria Bolin, Karl Svennersten, X Wang, \\ Agneta Richter-Dahlfors and Magnus Berggren
}

\section{Linköping University Post Print}

N.B.: When citing this work, cite the original article.

C2009 IEEE. Personal use of this material is permitted. However, permission to reprint/republish this material for advertising or promotional purposes or for creating new collective works for resale or redistribution to servers or lists, or to reuse any copyrighted component of this work in other works must be obtained from the IEEE.

Edwin Jager, Maria Bolin, Karl Svennersten, X Wang, Agneta Richter-Dahlfors and Magnus Berggren, Electroactive Surfaces Based on Conducting Polymers for Controlling Cell Adhesion, Signaling, and Proliferation, 2009, Transducers 2009: The 15th International Conference on solid-State Sensors, Actuators \& Microsystems, 1778-1781.

http://dx.doi.org/10.1109/SENSOR.2009.5285718

Postprint available at: Linköping University Electronic Press

http://urn.kb.se/resolve?urn=urn:nbn:se:liu:diva-53032 


\title{
ELECTROACTIVE SURFACES BASED ON CONDUCTING POLYMERS FOR CONTROLLING CELL ADHESION, SIGNALING, AND PROLIFERATION
}

\author{
Edwin W. H. Jager ${ }^{1,3,}{ }^{*}$, Maria H. Bolin ${ }^{1,3}$, Karl Svennersten ${ }^{2,3}$, Xiangjun Wang ${ }^{1,3}$, \\ Agneta Richter-Dahlfors ${ }^{2,3}$, Magnus Berggren ${ }^{1,3}$ \\ ${ }^{1}$ Department of Science and Technology, Linköping University, SE-601 74 Norrköping, SWEDEN \\ ${ }^{2}$ Department of Neuroscience, Karolinska Institutet, SE-171 77 Stockholm, SWEDEN \\ ${ }^{3}$ Strategic Research Center for Organic Bioelectronics, SWEDEN
}

\begin{abstract}
We report on a variety of electroactive surfaces for the control of in vitro cell adhesion, proliferation, and stimulation. Planar cell culture substrates have been coated with the conducting polymer PEDOT and by switching the redox state, adhesion and proliferation of MDCK epithelial cells was controlled as well as stem cell seeding density. Electronically active 3D-scaffolds based on electrospun PET nano-fibers coated with PEDOT have been used as a substrate to culture SH-SY5Y neuroblastoma cells and to induce $\mathrm{Ca}^{2+}$ signaling. Finally, we report on micromechanical stimulation of cells using an electroactive topography surface based on micropattened polypyrrole.
\end{abstract}

\section{KEYWORDS}

Organic electronics, conducting polymers, cell adhesion, surface energy, PEDOT, PPy, cell stimulation.

\section{INTRODUCTION}

Traditionally, in vitro cell studies are performed using planar and rigid Petri dishes comprising the cell culture and culture medium. Cellular responses upon exposure to various biomolecules are studied by adding these in solution to the medium. This is different from the in vivo situation where cells grow in a complex 3D environment. In this environment, they receive chemical and electrical signals from neighboring cells and from the extracellular matrix (ECM). In order to better mimic nature, a number of artificial surfaces have been developed such as microand nanotexturing [1, 2], fibers [3, 4], and coatings [5].

Electronics operate in a fundamentally different manner from biological systems: electronics is the domain of electrons and bio-systems are the domain of ions and molecules. Organic bio-electronics aims to combine and interface these worlds by utilizing the simultaneous electronic and ionic conduction present in conducting polymers.

Conjugated or conducting polymers (CP) such as poly(3,4-ethylenedioxythiophone) (PEDOT) and polypyrrole (PPy) can be electrochemically oxidized and reduced. This will change the material properties of the polymer such as conductivity, surface energy (wettability), color, and volume. The volume change can be utilized in $\mathrm{CP}$-actuators in various schemes such linear actuation, bulk volume change (piston), and bending mode by assembling the $\mathrm{CP}$ in a bilayer configuration. Furthermore, the CP-actuators can be miniaturized using standard photolithography and microfabrication methods [6]. In addition, the change in surface energy can be used to make wettability or surface energy switches [7]. It has been shown that this switching of the redox state of CPs influences the adhesion and proliferation of cells [8]. Finally, during synthesis of the $\mathrm{CP}$ a charged counter ion can be included in the polymer matrix. This counter ion can then be released upon electrochemical activation. By exchanging the counter ion for a biomolecule, electronically controlled release of substances can thus be achieved [9].

\section{PLANAR SURFACE SWITCH \\ Device fabrication}

When switching the redox state of PEDOT electrodes, i.e. oxidizing one side and reducing the other, the surface energy will change. Using this switching it was investigated whether the adhesion and proliferation of cells adhered on the surface could be influenced.

Electronically functionalized cell culture dishes were produced using chemical polymerization of PEDOT in petri dishes. A solution of EDOT monomers, the oxidant iron(III) p-toluenesulfonate (Tosylate), and the basic inhibitor pyridine in butanol was spin coated inside the petri dishes [10]. The petri dishes were then heated to facilitate chemical polymerization and to evaporate the pyridine. Residual iron was removed by sequential washes in butanol, isopropanol, and deionized (DI) water; thereafter the films were blow dried. The surface was then mechanically divided into two electrodes (Figure 1).

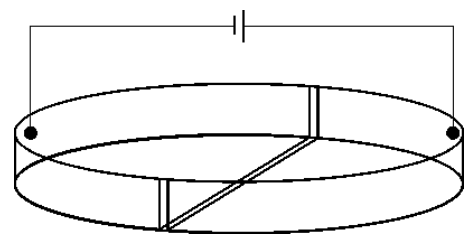

Figure 1. Functionalized petri dish consisting of two PEDOT coated electrodes that can be electrochemically switched, i.e. one electrode is oxidized and the other electrode reduced.

Upon applying a low potential of $1.0-1.5 \mathrm{~V}$ in the 
presence of an electrolyte, such as cell culture medium, the device functions as an electrochemical circuit. At the anode the PEDOT is oxidized and at the cathode the PEDOT is reduced. Since the PEDOT is electrochromic, the redox switch can be monitored visually as well. The color of the reduced electrode changes from blue to deep blue while the oxidized electrode turns more transparent.

Using this surface switch, two cell systems were studied. We investigated electronic control of the seeding density of c17.2 neural stem cells and adhesion and proliferation of MDCK epithelial cells.

\section{Neural stem cells}

Adhesion is an essential parameter for stem cells. It regulates the overall cell density along the carrying surface which further dictates the differentiation scheme of stem cells towards a more matured and specified population. C17.2 neural stem cells were seeded on the biased (1.5 V) PEDOT-coated dishes. After 2-4 h hours, the cells were fixed, stained with 4', 6-diamidino-2-phenylindole (DAPI), and counted. We found that the c17.2 cells preferred to attach to the oxidized surface (Figure 2a). The intrinsic adhesive properties of the cells were not changed by the surfaces they were presented. As the oxidation state of the conjugated polymer electrodes was controlled the seeding density could be varied by a factor of 2 (Figure 2b). Along the oxidized PEDOT:Tosylate-electrodes, a relatively lower density of, and less tightly bonded, Human Serum Albumin was observed as compared to reduced electrodes. We found that this favours adhesion of the specific stem cells studied [11].
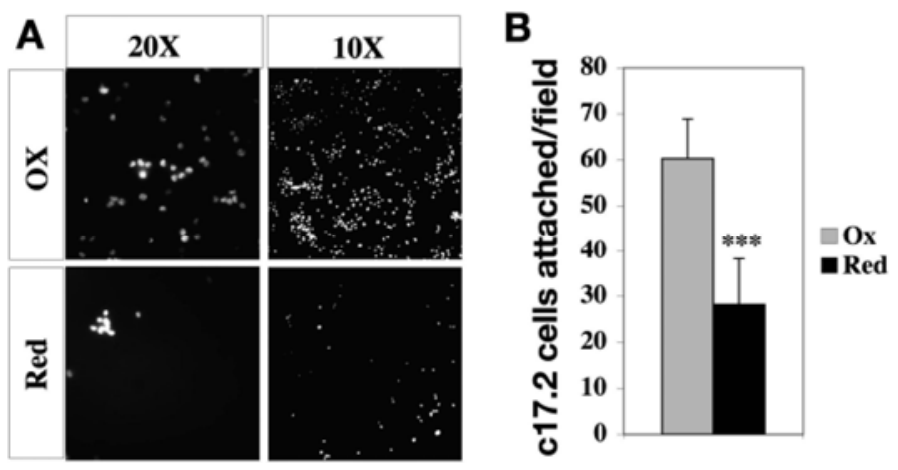

Figure 2. Differential attachment and cell density of c17.2 neural stem cells grown on PEDOT:Tosylate polymer dishes that were electronically switched into the oxidized and reduced states. (a) $20 \mathrm{X}$ and $10 \mathrm{X}$ magnifications show nuclei of the cells . (b) Histogram showing the average cell density (number of cells attached per field after 2 h) on oxidized and reduced PEDOT electrodes. Data are mean \pm standard deviation from triplicates in three independent experiments $(n=3), * * * p<0.001$.

\section{MDCK kidney cells}

In order to study the effect of the redox state of the conducting polymer on epithelial cell adhesion and proliferation, Madin Darby canine kidney (MDCK) epithelial cells were seeded on the biased (1.5 V) PEDOT electrodes and incubated at $37^{\circ} \mathrm{C}$ for $24 \mathrm{~h}$. Hereafter, the MDCK cells on the electrodes were stained for immunofluorescence microscopy analysis of adherent cells.

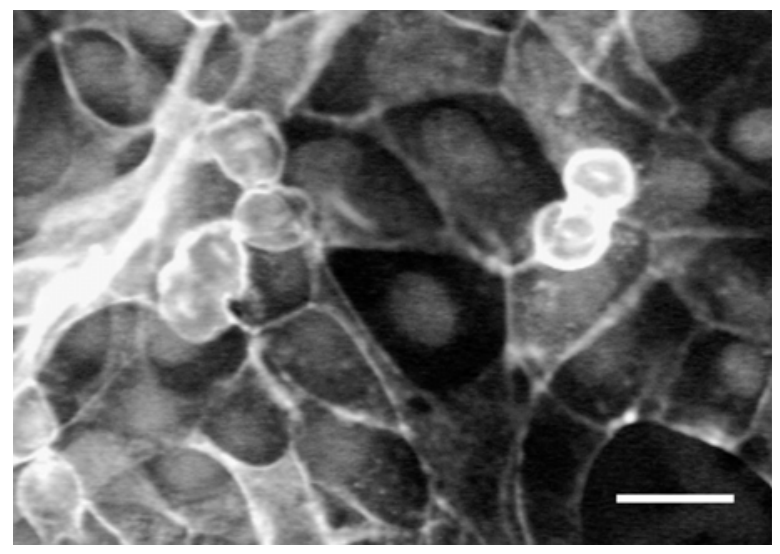

Figure 3. MDCK cells stained against actin and nuclei on the biased planar PEDOT surface switch. Scale bar $=200 \mu \mathrm{m}$.

The extracellular matrix protein fibronectin is important for cell adhesion. The contribution of fibronectin to the cellular response of the PEDOT redox state was investigated [12].

\section{FIBER SURFACE SWITCH}

The previous devices demonstrated that cellular adhesion and proliferation can be electronically controlled by changing the redox state of the conducting polymer surface. However, these devices still present a planar geometry different from the 3D environment of cells in vivo, including the fibreous ECM.

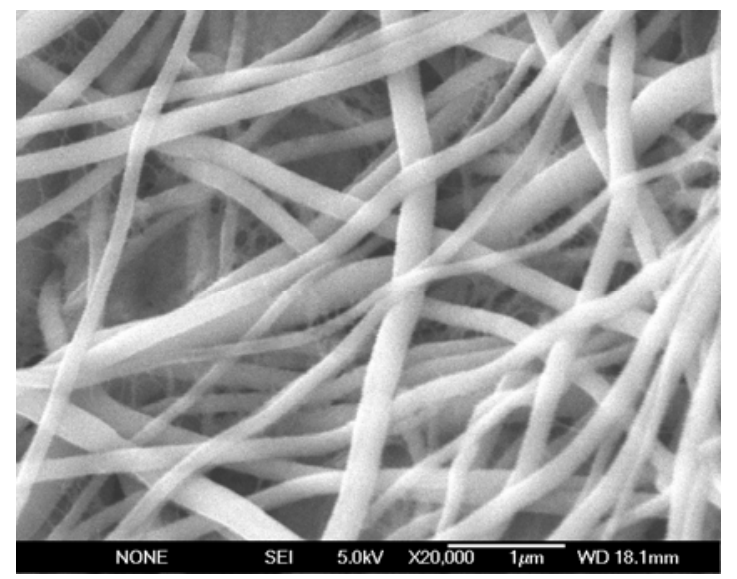

Figure 4. SEM picture of PEDOT:Tosylate coated PET fibers using vapor phase polymerization.

In order to convert these planar electrodes into 3D scaffolds, poly(ethylene terephthalate) (PET) nano-fiber 
mats were fabricated using electrospinning. Hereafter, vapor phase polymerization was employed to coat the nano-fibers with a PEDOT:Tosylate layer [10]. The nanofiber mats were spin coated with an oxidation solution comprising $\mathrm{Fe}(\mathrm{III})$ tosylate in butanol and pyridine. Hereafter, the substrates were exposed to EDOT monomer vapor resulting in a coating of PEDOT on the nano-fibers (Figure 4).

Two PEDOT coated nano-fiber mats were mounted into a custom-made petri dish resulting in a similar set-up as the planar surface switches. Electrical contacts were made with conducting copper tape.

Undifferentiated SH-SY5Y human neuroblastoma cells were cultured on the PEDOT coated nano-fiber mats for 24-48 h. The SH-SY5Y cells adhered well and showed healthy morphology (Figure 5). These electrically active scaffolds were used to induce $\mathrm{Ca}^{2+}$ signaling in SH-SY5Y neuroblastoma cells. It was shown that PEDOT coated nano-fibers can be utilized as 3D host environments that combine excellent adhesion and proliferation for neuronal cells with the possibility to externally regulate their signaling, such as electrically stimulated $\mathrm{Ca}^{2+}$ signaling [13].

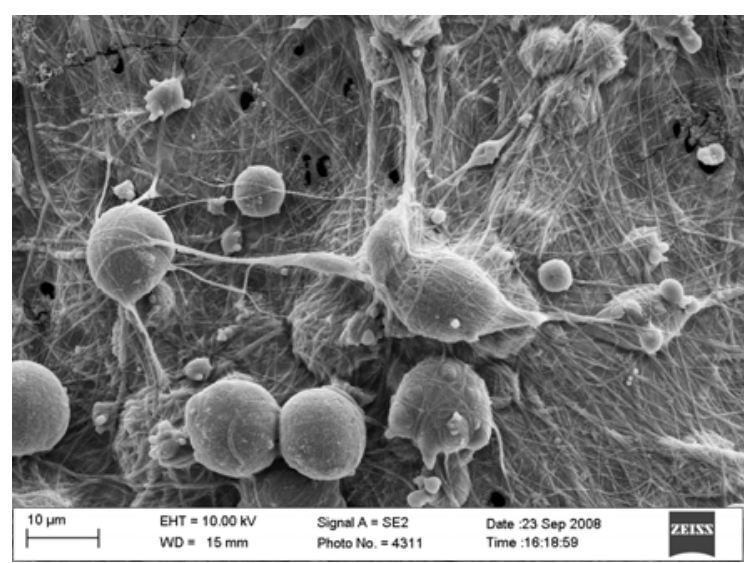

Figure 5. SEM image of SH-SY5Y cell growing on PEDOT coated fibers. Scale bar $=10 \mu \mathrm{m}$.

\section{TOPOGRAPHY SWITCH}

Next, electroactive mechanical control of 3D surface was introduced by developing micromechanical topography switches. Microstructured polymer surfaces were prepared for electrochemically induced morphology switching. This was achieved by exploiting the large perpendicular volume change of PPy [14]. Micropatterned PPy was combined with inert SU-8 microstructures [15]. The surface consists of SU-8 square pillars (100 $\mu \mathrm{m}$ wide and $16.8 \mu \mathrm{m}$ high) surrounded by a PPy mesh $(100 \mu \mathrm{m}$ wide and $12.7 \mu \mathrm{m}$ thick). In order to see the effect of the raising PPy mesh in the SU-8 pillar area, contact angles were measured. The dynamics of the topography switch upon sequential reduction-oxidation switching, were recorded ex situ by SEM and Dektak profilometry (Figure $6)$.

In the microstructured surfaces redox switching results in an alteration of the PPy thickness, i.e. the depth between the SU-8 pillars alters. In the first switch cycle, the PPy thickness was varied from $12.7 \mu \mathrm{m}$ to $13.8 \mu \mathrm{m}$ upon reduction to the neutral state. We clearly observed how application of the cathodic potential leads to the raising of the PPy mesh. The expansion ratio of the initial reductionoxidation cycle was $9 \%$. This is slightly less then what has been observed by others, where ratios of $20-30 \%$ have been measured on micropatterned PPy structures [14]. As shown in Figure 6e the volume change is not fully reversible, which is generally the case for PPymicroactuators [6].
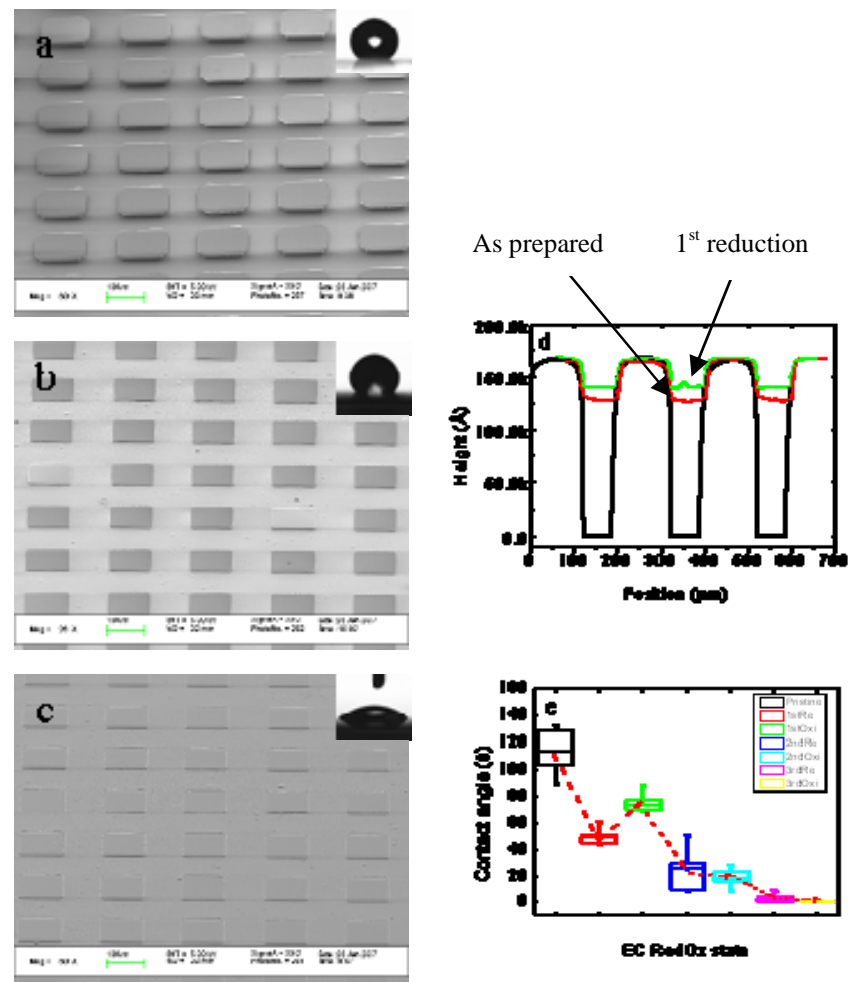

Figure 6. SEM images of (a) SU-8 square pillars, (b,c) PPy electropolymerised $(12.8 \mu \mathrm{m})$ forming a mesh surrounding the SU-8 pillars (16.8 $\mu \mathrm{m})$ (b) as-prepared and (c) after reduction. Scale bar $=100 \mu \mathrm{m}$. (d) Dektak profile of the micro-patterned surfaces; before (black solid line) and after adddition of PPy, and after the first reduction switch. Insets in the top right corner of the SEM are (a) $148^{\circ}$, (b) $129^{\circ}$, and (c) $44^{\circ}$ contact angles of the droplets on the as-prepared surfaces. (e) The contact angle on the surfaces at different EC states.

Upon redox switching the contact angle varied typically between $\theta_{\mathrm{ox}} \approx 80^{\circ}$ (oxidized state) to $\theta_{\mathrm{ox}} \approx 50^{\circ}$ for flat PPy surfaces. The addition of the micropattern radically increases the change in contact angles upon redox switching (insets, Figures 6a-c). In the first redox cycle the contact angle decreased from $\sim 129^{\circ}$ to down to $\sim 44^{\circ}$. 
In the second redox cycle, the corresponding values were from $\sim 74^{\circ}$ down to $\sim 26^{\circ}$, respectively.

A second generation of topography switches dedicated for micromechanical stimulation of cells has been designed and fabricated. MDCK cells were grown overnight on fibronectin coated topography switches. Cells were then loaded with Fluo-3 and monitored using confocal microscopy. Micromechanical stimulation of the topography switch induced $\mathrm{Ca}^{2+}$ signaling of the seeded cells.

\section{REFERENCES}

1. R.G. Flemming, C.J. Murphy, G.A. Abrams, S.L. Goodman, P.F. Nealey, "Effects of synthetic microand nano-structured surfaces on cell behavior", Biomaterials, vol. 20(6), pp. 573-588, 1999.

2. C.D.W. Wilkinson, M. Riehle, M. Wood, J. Gallagher, A.S.G. Curtis, "The use of materials patterned on a nano- and micro-metric scale in cellular engineering", Materials Science and Engineering C, vol. 19(1-2), pp. 263-269, 2002.

3. M.P. Lutolf,J.A. Hubbell, "Synthetic biomaterials as instructive extracellular microenvironments for morphogenesis in tissue engineering", Nature Biotechnology, vol. 23(1), pp. 47-55, 2005.

4. J. Venugopal, S. Low, A.T. Choon, S. Ramakrishna, "Interaction of cells and nanofiber scaffolds in tissue engineering", Journal of Biomedical Materials Research - Part B Applied Biomaterials, vol. 84(1), pp. 34-48, 2008.

5. G.X. Wang, X.Y. Deng, C.J. Tang, L.S. Liu, L. Xiao, L.H. Xiang, X.J. Quan, A.P. Legrand, R. Guidoin, "The adhesive properties of endothelial cells on endovascular stent coated by substrates of poly-Llysine and fibronectin", Artificial Cells, Blood Substitutes, and Biotechnology, vol. 34(1), pp. 11-25, 2006.

6. E.W.H. Jager, E. Smela, O. Inganäs, "Microfabricating Conjugated Polymer Actuators", Science, vol. 290(5496), pp. 1540-1545, 2000.
7. J. Isaksson, C. Tengstedt, M. Fahlman, N. Robinson, M. Berggren, "Solid-state organic electronic wettability switch", Advanced Materials, vol. 16(4), pp. 316-320, 2004.

8. J.Y. Wong, R. Langer, D.E. Ingber, "Electrically conducting polymers can noninvasively control the shape and growth of mammalian cells", Applied biological sciences, vol. 91, pp. 3201-3204, 1994.

9. L.L. Miller, "Electrochemically Controlled Release Of Drugs And Other Chemicals", Reactive Polymers, vol. 6(2-3), pp. 341-341, 1987.

10. B. Winther-Jensen, D.W. Breiby, K. West, "Base inhibited oxidative polymerization of 3,4ethylenedioxythiophene with iron(III)tosylate", Synthetic Metals, vol. 152(1-3), pp. 1-4, 2005.

11. C. Saltó, E. Saindon, M. Bolin, A. Kanciurzewska, M. Fahlman, E.W.H. Jager, P. Tengvall, E. Arenas, M. Berggren, "Control of neural stem cell adhesion and density by an electronic polymer surface switch", Langmuir, vol. 24(24), pp. 14133-14138, 2008.

12. K. Svennersten, M. Bolin, E.W.H. Jager, M. Berggren, A. Richter-Dahlfors, "Adhesion and viability of MDCK cells controlled by a PEDOT:Tosylate surface", Submitted, 2009.

13. M. Bolin, K. Svennersten, X. Wang, I.S. Chronakis, A. Richter-Dahlfors, E.W.H. Jager, M. Berggren, "Nanofiber scaffold electrodes based on PEDOT for cell stimulation", Submitted, 2009.

14. E. Smela,N. Gadegaard, "Surprising volume change in PPy(DBS): An atomic force microscopy study", Advanced Materials, vol. 11(11), pp. 953-957, 1999.

15. X. Wang, M. Berggren, O. Inganäs, "Dynamic Control of Surface Energy and Topography of Microstructured Conducting Polymer Films", Langmuir, vol. 24(11), pp. 5942-5948, 2008.

\section{CONTACT}

* E.W.H. Jager, tel: +46-11-363446; edwin.jager@itn.liu.se 